\title{
Nationalist Hindi Cinema
}

\author{
By Valentina Vitali
}

Fall 2004 Issue of KINEMA

\section{NATIONALIST HINDI CINEMA: QUESTIONS OF FILM ANALYSIS AND HISTORIOG- RAPHY}

The forty years or so from the beginning of cinema world-wide at the end of the nineteenth century to the consolidation of a domestic film industry in South Asia in the 1930s coincided with the project of nationbuilding that envisioned a variety of horizons, and with the sedimentation of some of those prospects into the coalition ready to inherit the rule from the British Raj. Cinema played a crucial role in mediating the terms by which India came into being as a modern nation.

As Ernest Gellner saw it, it is the homogenizing effect of an economic system such as industrial capitalism, and, within it, the occupational mobility and the division of labour leading to the breaking down of preindustrial, hierarchical, self-contained social categories, that lead to the "invention" of nationalism. With the advent and spread of capitalism, "culture is no longer merely the adornment, confirmation and legitimation of a social order [...]; culture is now the necessary shared medium, the life-blood or perhaps rather the minimal shared atmosphere, within which alone the members of the society can breathe and survive and produce. [...] But some organism must ensure that this unified culture is indeed being effectively produced. $[\ldots]$ That is what nationalism is about, and why we life in an age of nationalism." (Gellner 1983: 37-38).

From the point of view of a historically pertinent understanding of cinema as a social practice involved in the construction of national identities, the biggest problem with Gellner's theory is less the claim that nations are an effect of nationalism (and nationalism of industrialisation), and more the reduction of culture to education, that is, to a project undertaken by the state and therefore fully instrumentalised for the social and economic trajectory preferred by the dominant coalition within any given nation. Which is why Gellner could conceive of national culture as "unified".Writing in the mid nineteenth century, Otto Bauer contested the idea, then held by many on the Left, that modern society would result in a sort of flat, uniform cosmopolitanism. He stated that all modern nations experienced industrial capitalism in similar ways, but they did not experience it in common. Commonality, cutting across class lines, linked specific groups by what he called "community of destiny", read not quasi-metaphysically as ancient doom, but as shared will towards the future. This will, which is subject to constant change also within the one nation in the struggle for life of its citizens, is precipitated through shared language, habits of everyday life, shared culture and, eventually, shared political institutions (Bauer 1996: 4). Both as an industry and as a series of filmic texts, cinema in South Asia (as elsewhere) has never offered "reflections" of a pre-existing, linear process of nation-building. It is, rather, the other way around: cinema has always been the adjunct of a process of industrialisation, of which both nationalism and films are products. And just as films can differ one from the other, so can diverse, even contrasting "nationalisms" - intended as shared wills for the future - manifest themselves within the one nation. In spite of this, the notions of history and of culture that underpin much film historiography today hardly help to understand exactly how cinema interconnects South Asians into what Bauer called "a community of destiny:" that is to say, into a discursive field over which the trajectory of independent India in its encounter with capitalism was, and continues to be, negotiated, distinctly from the institutions of the state, by interest groups which may and may not be the dominant ones at any given time.

One of the most influential models of nationalism available to the Congress in the run up to independence was the USA. India was not unique in this respect; whether as a constitutional model or as an economic power, by the 1930s the USA were emulated and aspired to by most national political formations, in the First as much as in the Third world. First published in 1939, Lewis Jacobs' The Rise of the American Film: a Critical History was not only the first biography of a national cinema, but also the apotheosis of all other cinemas' most powerful competitor. Unsurprisingly, most historiographies of national cinemas came to be narrated on the blueprint of Lewis Jacobs' book.

The Rise of the American Film used a linear model of history that Jacobs derived from (American) nationalism: the founders, the coming of sound, the studios and, within them, the great auteurs. Within this 
evolutionist frame, the set of conventions dominant in nineteenth and early twentieth century European and American literature and the "fine arts", namely, the conventions of Realism, were adopted as the preferred criteria for "good" or "mature" cinema. Indian Film (Barnouw and Krishnaswamy), a book that has demarcated the study of Indian cinemas since its publication in 1963, closely followed the path laid out by Lewis Jacobs: the beginnings of cinema in "India" with the Lumière brothers' screening in Bombay in 1896; the founder, Dadasaheb Phalke, a photographer born into an upper-caste family and a committed nationalist; the coming of sound, which helped consolidate a domestic film industry producing and exhibiting films in the local languages; and the rise of a studio system around New Theatres, in Calcutta (producing Bengali films), the Prabhat Film Company, in Pune (making films in Marathi, Hindi and some in Tamil), and Bombay Talkies, in Bombay. Finally, in the run up to 1947, the emergence of an indigenous form of film realism and concomitant auteurs out of New Theatres.

There are enormous problems with this account of the cinema in India. There is, to begin with, an issue of terminology: whereas the first films recorded to have been made by South Asians date back to 1897, India did not come into being as a nation-state until 1947. As the editors of the Encyclopaedia of Indian Cinema observe, to frame an understanding of Indian film within the geo-temporal frame constituted by the Indian nation-state since Independence, or more accurately, since Partition, would require us to rule out any engagement with the longer-term dynamics which have shaped post-Partition Indian cinema. (Rajadhyaksha and Willemen 1999: 9). It is not simply a matter of what individual accounts of a national cinema leave out - early cinema film-makers such as Paul Zils, a UFA director born in Wuppertal (Germany) who was to become an influential figure in Indian documentary cinema - but, more importantly, of the obstacles posed by (some) historiography to an understanding of ourselves as cultural subjects. In Indian Film the adoption of the American blueprint produced not only exclusions which accumulate into a historically incorrect account of what the cinema was in India before and after 1947, but also a view of Indian cinemas as "still developing", less refined versions of European and American cinemas.

The narrative strategies of American and European cinemas, partly derived from visual perspective as it developed in early modern Europe, can be used to construct a mobile and subjective observer. The exemplary strategy for subjective narration in these and other cinemas is the reverse angle: a shot lets us see a piece of space; the reverse angle shows us the space in which we were assumed to have been a moment earlier, situating us in the space we were just looking at. As Gilbert Perez observes, "such [a] reversal does away with the theatrical demarcation between the space of performance, which belongs to the actors, and the space from which we watch the performance. The reverse angle usually pivots us on a character's glance. It identifies the character's eyes with our own by cutting to what is in front of them, so that we see what they are seeing, not necessarily from their exact point of view [...] but from their side of things. It invites us inside and puts us in the position of the characters." (Perez 2000: 24). Strategies such as the reverse angle allow the film spectator to shift to and fro characters. The narrator - as the agent orchestrating what the film spectator is given to see - can and often does delegate narration to a character. "It", and we with it, attaches itself to, and takes up points of view that move across a broad range of social classes, gender and other social markers.

Divided into six parts - significantly entitled "Fade In", "Foundations", "Development", "Transition", "Intensification" and "Maturity" - The Rise of the American Film rested on three assumptions that are highly problematic - not least because, taken separately, each of the assumptions has long been disputed by the respective disciplines. Namely (a) that the historical dynamics underpinning Euro-American cinemas involve an evolutionary trajectory from European feudalism to North American modernity; (b) that this process was given rise by a bourgeois consciousness understood to be fully modernised; and (c) that the cinematic forms that emerged in the process - such as the reverse angle described above - are inherently symptomatic of that consciousness, of a mobile and emotionally emancipated individual.

That the historically specific voices activated through arrangements of narrative forms must not be taken to be self-evident is made dramatically clear when the terms of the analysis developed in the context of one set of conventions - here European and American cultures - are transposed to a consideration of texts that operate with different meanings implied by the available forms, different speaking positions attaching to the narratorial agency. The assumption that the strategies found in American and European cinemas are inherently symptomatic of an individuated narratorial agent has caused endless problems to historians of 
cinemas that are not European or American because, having identified in these cinemas narrative strategies that differ from those at work in the cinemas of constellations said to be fully modern, the only option open to film historians within this linear model of history is to take the strategies of those "other" cinemas to be indicative of "pre-modernity". All of which leaves one with no option on another front: that is, to live with the contradiction of an industrial cultural practice functioning on the basis of pre-modern cultural forms.

The debate on "frontality" is a case in point. Frontality is here connected to the way in which the term "iconicity" has been used by Geeta Kapur and other cultural historians: both refer to a kind of direct address to the viewer by way of a frame arranged in a 180 degrees space - as opposed to a 360 degrees space - such as the proscenium of a theatre. The cinematic frontal address has been discussed as a "pre-modern" form not so much because it is reminiscent of the theatre proscenium, or because it may require a lower level of technology than, say, a mobile camera, but because it is perceived to convey a static point of view and, to that extent, to be an obstacle to the subjective and mobile narration effected by strategies such as the reverse angle. In contrast to the latter, a frontal mode of address fixes the viewer within a more strictly ordered spatial hierarchy, treating the film frame as a flat surface and allocating spaces to the characters and other diegetic elements on the basis of their status or position within a pre-established hierarchy. Whereas within a perspectival system the rendition of "reality" changes depending on the observer's point of view, the frontal frame presents the viewer with a "reality" that is given and unchangeable. There is no place here for the viewer to roam. The order of reality is determined not by the position of a character in its dynamic inter-relation with other elements in the diegesis, nor by the narrator's orchestration of those relations or points of view, but by an all-encompassing, monocular subject that conveys Gods' eye view.

Frontality and iconicity often involve emphasising action as being "signified" rather than performed. Performing an action is a way of doing things; a gesture, on the other hand, is the movement of any part of the body to signify an idea or concept (Barthes 1977). While a gesture presupposes a sender and a receiver of a coded message, the performance of an action does not necessarily assume the absence of an addressee, but it includes that possibility. A "signified" action presupposes a viewer, or rather, inscribes the spectator in the text as an active element, a presence to whom the gesture is addressed, often emphatically. Unlike in a 180 degrees frontal space, such as the proscenium theatre, within the 360 degrees space the spectator is imagined as absent while the actors' performance is marked by expectations of naturalism.

Hollywood cinema, from musicals to Rambo films, does resort to frontal modes of address. As a rule, however, European and American films rest more heavily on a 360 degrees space than Indian, or, for that matter, Japanese films. The option preferred by film historians faced with an industrial practice mobilising narrative strategies that, like frontality, are deemed to be inherently "pre-modern", has tended to be to "resolve" the contradiction by way of mystifying notions of "stylisation" or of avant-gardistic Verfrendumg. Alternatively, narrative strategies such as frontality have been dismissed as the troubles and inconsistencies of an unpolished, "still developing" cinema. In the latter case, the assumption is that these cinemas are travelling in the same direction of American and European cinemas, even if they are not quite there yet.

In relation to the cinema in India, the matter of frontality was raised by Indian cultural and film historians Geeta Kapur and Ashish Rajadhyaksha. Rajadhyaksha has pursued Kapur's line of argument in relation to the cinema of Dadasaheb (Dhundiraj Govind) Phalke (1870-1944), a pioneering director who is claimed to have started the film industry in India. Phalke, a committed nationalist, saw his cinema as a contribution to the struggle for self-rule. His films, like all early Indian cinema, were overdetermined by the film-maker's encounter with a contradictory object: a regressive colonial rule that presented itself as modern and which addressed him in terms of Empiricist notions of historical truths and $19^{\text {th }}$ century expectations of realism in fiction. For this reason, Phalke entertained an oblique relation to the codes of cinema as it was made in Europe and the US. Seeking to displace colonial accounts of reality as "untrue", he set out to occupy a frame and a cinematic apparatus that they perceived as "Western" with "Indian images", in the process effectively incorporating also orientalist constructions of South Asia as a "pre-modern" society, steeped in religious beliefs and mythological narratives. As Rajadhyaksha has convincingly argued, this was one of the reasons behind Phalke's choice of material, often from Hindu mythology, as well as for his use of a frontal address and a 180 degrees space, which Phalke recovered from, among other sources, the Parsee and Marathi theatres (Rajadhaksha 1987). 
In the context of Hindi melodrama, the question of frontality has been addressed most directly by Indian historian Ravi Vasudevan. In a series of seminal essays, Vasudevan has argued that Hindi cinema relies, on the one hand, on the narrative strategies that are also at work in Euro-American cinemas - such as the reverse angle and spatial continuity from one shot to the next - and, on the other, on iconic or frontal modes of address that appear to interfere with perspectival narration. For instance, in Andaz (Mehboob Khan 1949) an image of Hindi star Nargis interrupts and is lifted out from the spatial relations established until that point in the scene, as if to be presented to the viewer for special contemplation. The resulting effect is a type of frontal iconicity that, Vasudevan maintained, bespeaks of a pre-modern social code in which subjectivity is constructed by "definite points of authority and notions of conventions" (1993).

Vasudevan developed this line of argument by borrowing the notion of frontality as used by Geeta Kapur in her discussions of South Asian painter Ravi Varma's paintings (1989), but frontality or iconicity in cinema require more remarks than Vasudevan's argument allows. Whereas in painting the composition of a tableau can be fairly uncontroversially identified as frontal, it is not so easy to do this in cinema, where frontal views are stitched together into a continuous flow in order to produce narration. Besides it could equally be claimed that the image of Nargis in Andaz "tends to work against the development of the story line, to freeze the flow of action in a moment of erotic contemplation" (Mulvey 1975), thus effectively inscribing the viewer as an individuated, desiring (male) subject, rather than a pre-modern one defined by hierarchical social structures and conventions. To reduce the frontal address in cinema to a device constructing a pre-modern subjectivity is a historically incorrect reading of an industrially produced strategy in the functioning of which are several co-existing relays of pre-industrial and industrial temporalities and social forces, each struggling to emerge as dominant and, from that position, claiming to narrate "the truth". (1)

Frontality is part of the narrative stock available to all cinemas, including mainstream Hollywood films, and better ways must be found to grasp the diverse manners in which this, along with other devices, functions as a fundamental element of narration. How to establish with some accuracy the factors that determine the substance of the same narrative form as it plays in different cultures? The American culture industry may well be in a position to dictate the terms by which other countries produce and circulate films, but this does not mean that the economic measures designed to safeguard Hollywood's dominance should define the terms by which film critics and historians ascribe value to films and assess their social productivity. Given the context outlined above, frontality can serve as a point of departure to redefine the terms of a debate that, seventy years after the publication of The Rise of the American Film, is still wholly overdetermined by the centrality of the United States as an economic and cultural force. My objective, in the analysis that follows, is to demonstrate the productivity of a comparative framework capable of examining any cinema as a cluster of discursive technologies - some of recent formation, others very old indeed - the semantic modulations of which in any given film are presided and contended over by the historically specific temporalities and social forces at work "outside" the text. From this perspective films are not "representations" of a vaguely defined "context". Rather, as adjuncts to a society's encounter with industrialisation, films stage that very encounter over the narrative stock available to them and its redeployment under changing conditions of cultural production. The resulting tensions within any one film over the uses and meanings of its forms offer a partial snapshot of how the temporalities and interest blocks involved in a society's push-and-pull towards modernization position themselves.

What is at stake in this approach - based on a non-linear notion of history and on an understanding of cultural forms as accessible for mobilisation by a variety of forces - is the possibility of a new research agenda: one that can begin to open up new lines of enquiry on Indian and other cinemas, including Hollywood and the new ways of posing the question - too often dismissed or reduced to trivial reflectionisms - of how a film may relate to the socio-economic fabric that underpins it. After a detour via a Hindi film, I will thus conclude by drawing attention to some of the implications of the kind of framework used here for the study of, and future research on, Hindi cinema.

Shaheed (Martyr, Ramesh Saigal) is ideal material to examine the uses of frontality in industrial cultural production. This Hindi film was made by Filmistan - a Bombay-based studio established in 1943 by a breakaway group from Bombay Talkies that elaborated the conventions of earlier studios into the first consistent generic codifications of a post-Independence all-India film market while revolutionising distribution with mid-budget genre productions selling on their star and music value (Rajadhyaksha and Willemen 1999: 
95). A hit single-handedly responsible for establishing the famous star pair Dilip Kumar and Kamini Kaushal, Shaheed was especially screened for the Congress Party's All India Committee in April 1948, before its commercial release in Bombay in August 1948, in time for the first anniversary of Indian Independence (Desai 2004: 33).

The film tells the story of Ram (Dilip Kumar), the son of a colonial officer and a fervent nationalist, who leaves home to join a group dedicated to armed struggle (qualified as "terrorist") in spite of his father's disapproval. Wounded, he is looked after and protected from arrest by his childhood sweetheart, the rich and aristocratic Sheela (Kamini Kaushal) who grew up to become a doctor. Sheela's brother, the non-violent Gopal, is arrested by Vinod (Chandramohan), the childhood friend of both Sheela and Ram who has become a colonial police officer. Although in love with Ram and sympathetic to the nationalist cause, Sheela is forced to marry Vinod in exchange for Gopal's freedom and Vinod's promise to save Ram's life. Ram thinks himself betrayed by Sheela until the end, when, discovering the truth, he decides to abandon violence. Accused of terrorist activities, Ram is defended in court by his now repentant father, but is nevertheless hanged. He dies, but not without the consoling thought that he is finally reconciled with Sheela, who has also died, and with his father.

Shaheed opens with a sequence that relies heavily on frontal modes of address. After a title card setting the historical time and a shot of the Indian flag against the sky, the film evokes from the start the reality of colonial rule: policemen open fire on a peaceful nationalist demonstration . The hero's father, an Indian colonial officer, is with other officials on the balcony of an adjacent building, overseeing the shooting. The camera is positioned behind and above the heads of the demonstrators, who have their back to the camera. We see the crowd, below eye-level in the foreground, and the colonial officials, facing us in the background. The next scene takes us into a home and shows the young hero, Ram, his friends, Sheela and Vinod, and Ram's mother. On the wall of the living room, in the background, hangs a framed photograph of Ram's father and one of the English queen. The camera is fairly static and the scene is presented frontally, as a kind of family tableau. Ram tells his mother he wants to be like Nehru. Sheela and Ram fight with Vinod because of his Western clothing. Intervening, the mother asks: "Would Nehru beat people up?" We then cut to a new scene, a theatre, in which school children (including Ram, Sheela and Vinod) are staging a nationalist play. In the play, Nehru joins a nationalist demonstration, pleads for non-violence and is arrested by colonial officers. Discernible among the small audience are Ram's mother and Sheela's father, who watch the performance approvingly. The camera shifts from stage to audience as two complementary and equally frontally presented sites. Eventually, from the stage, we see Ram's father joining the audience and ordering that the performance be stopped immediately.

A sense of discrepancy between reality and its representation emerges right from the start as a significant factor in the narrative. The film is prefaced by a heavily marked nationalist discourse which designates itself in the first visual of the movie, the flag of Independent India. However, this flag introduces a story starting prior to Independence and Partition while marking the time of the enunciation of the film, which is 1948. Furthermore, the theatre play staged by the children tells the truth about colonial rule as the film wants us to accept it, but this is a truth that Ram's father deems to be untrue. The family tableau presents yet further stratifications at a number of different levels. There is, for instance, the disruptive emergence of a nationalist discourse by way of a theatrically staged family scene from which the father is missing and in which, as the viewer soon learns, the children are not part of the same nuclear family. Ram, who professes to want to become like Nehru, telescopes both tradition (the name Ram and the character's dress code) and modernity (the reference to Nehru, the nationalist figure-head standing for a modernising Independent India), while Ram's antagonist, Vinod, wears Western clothing, thus evoking another type of modernity, anchored here by framing Vinod against a picture of the English queen. Ram and Vinod then come to blows precisely over the difficult task of how to reconcile all these discrepancies within one familial space.

The nationalist demonstration and the nationalist play posit the truth of things in the colonial public spheres, while the family tableau presents nationalism as a discourse pertaining to the domestic sphere. By stitching together a number of different discourses concerning alternative conceptions of modernity and tradition, framed by both the discourses of official history (the flag and the pictures of the heads of state hanging on the walls) and by the mother's unifying function, the space of nationalism is condensed and represented here as a domestic, family space. It is a space that shows all the features of what Partha Chatterjee designated 
as "political society" (1998), as distinct from the colonial public sphere. It is in, or, rather, over the latter that Ram's subsequent armed struggle will take place.

The story then jumps, via a written text, several years ahead to focus on the three main characters' adult life. A scene indicative of Shaheed's rendition of the struggle over the definition of a public sphere takes place in the forest, at an enclave of guerrilla fighters led by the adult Ram. As the sentinel alerts the fighters that colonial forces are on their way, Ram orders his soldiers into position. Hiding behind a rock and watching the colonial army approaching, Ram soon realises that the colonial force is led by none other than his childhood friend Vinod. The ensuing battle between Ram and Vinod's forces is presented primarily through the point of views of Ram and his soldiers. However, as the battle reaches its climax - the encounter between Ram and Vinod - Ram must decide between his duty as a nationalist soldier, which would require him to kill Vinod, and his love for Sheela, whom Ram believes to be in love with Vinod. At this point the camera starts oscillating between, on the one hand, views of the encounter from Ram's subjective point of view, and, on the other, frontal views of the two protagonists as they fight. One such oscillation is introduced by a tilting of the camera, which, marking the shift from a 360 degrees to a 180 degrees space, transforms Ram's subjective point-of-view into that of an emphatic narrator. Through the tilted camera we see, on the right bottom end of the screen, Vinod laying on the ground, while on the left is visible the end of Ram's gun. The camera then pulls out to show Ram advancing from the top left of the screen towards Vinod. The resulting frame is a static and frontal view of the two characters. We no longer take up Ram's viewpoint; rather, we look at the two figures from the perspective of an abstract, external agent whose capacity to convey meaning - here the struggle between the nationalist Ram and the colonialist Vinod - depends on a two-dimensional splitting of the frame into two areas and on the allocation of these symbolic spaces (the top and bottom of the frame) to the two characters.

In their discourse on Indian nationalism, these few scenes indicate that because of India's encounter with a contradictory and, deeply regressive force that addressed Indian people by way of narrative strategies such as visual perspective and psychological realism, Shaheed resorts to a frontal mode of address as a "degree zero". Deviations from the frontal address are, to use Jakobson's distinction, the "marked" terms. It is as if the frontal frame - characterised by the absence of a specific point of entry into what is given by the camera to be seen as "the real" - provided an abstract space marked as no more than "Indian nationalism". It is at the level of romance, that is, at the level of emotional involvement and desire, that the film offers a point of entry into what is and isn't the "Indian nation".

Frontality recurs whenever the credentials of Ram as a nationalist hero require reinforcing or simply stating. It pervades Ram's characterisation as a hero, and this, in turn, appears to interfere with the perspectival address used to characterise Ram in the "romance" layer of the story. In a scene that is representative of many romantic moments in Hindi melodrama of the 1950s, Ram, wounded, is taken into hiding in a hotel room by Sheela. The couple is alone for the first time since childhood and they declare their love for each other, even if by now Ram knows Sheela to be engaged to the colonialist Vinod. As the scene develops, Ram addresses Sheela, who is next to him but looks ahead, towards the camera. He says: "Tonight you are getting engaged to Vinod. If you are not home, there will be gossip. You will get a bad name. I need my respect, even if you don't. Go away. We've got nothing to say to each other." This dialogue immediately situates Ram and Sheela's romance within the frames of a trope - the impossibility of love across caste boundaries - that was first staged by Devdas (P.C. Barua 1935), the archetypal Hindi melodrama. Here, however, the obstacle to the fulfilment of romance has shifted: not caste barriers but Vinod and Ram's different positioning within, and legitimation by, the public sphere. While the adaptation of Devdas' trope marks a shift from colonial to nationalist India, the notion of honour - a pre-modern notion - is carried over into the nationalist and modern Indian constellation, fought for and represented by Ram.

From the beginning and throughout the protagonists' dialogue, Ram is shot frontally, while Sheela is allocated a perspectival, subjective point of view. While we look at Ram from Sheela's point of view, but whether or not Ram looks at or talks to Sheela, the camera is positioned in front of him, so as to enable the spectators to look at Ram. Paradoxically, such clear-cut allocation of perspectival and frontal addresses marks a point where the film enters a field of uncertainty. Ram is divided between his nationalist activities and his love for Sheela. The camera reflects Ram's quandary: the continuity between Sheela's subjective view of Ram and Ram's viewpoint, that is, the flow of looks between the two, is constantly blocked by the need to invest the 
hero with the frontality characteristic of his public, nationalist persona. ${ }^{(2)}$

It is worth comparing this scene with the romantic scenes in Sohrab Modi's Nausherwan-e-Adil/Nausherwan$e$-Adil (1957). (3) Modi's film tells the story of the forbidden love between king Nausherwan's son, Naushazad, and Marcia, the daughter of a Christian doctor. Made nine years after Shaheed, Modi's film always depicts the interaction between the lovers frontally, often through a static camera. A typical instance shows Naushazad and Marcia on a bench in a garden, singing. They are both sitting with their bodies facing the camera and heads turned to look at each other. The lovers' position makes it clear that a viewer is present and looking. This mise en scène precludes a sense of privacy, not only for the characters, whose position signal that they remain under the scrutiny of the viewer, but also for the viewer, who is equally pinpointed by the actors' frontal address.

The use of frontality in Shaheed is more complex than in Modi's film. To begin with, the camera is mobile. Unlike Modi's film, where Naushazad's position determines the camera's, so that the latter can endow the royal hero with the static centrality owed to his high status in a hierarchical system, here Ram's position determines the camera's not to invest him with royal status, nor to take up his point of view as a subjective individual, as it does for Sheela, but to ascribe to Ram the heroic centrality owed, in 1948, to a nationalist committed to a project of social modernisation. The spatial discontinuities that characterise this scene - triggered by the need to follow Ram's movements as he walks around the room, addressing, but never looking at, Sheela - result from an attempt to guarantee a view of the hero as a terrain encompassing both national (or public) and personal (or subjective) perspectives. So, while the aristocratic and modern Sheela is allocated a subjective point of view throughout, Ram's posture betrays a tension over the uses and meanings of frontality.

The key to this formal tension lies in the character of Sheela and what she represents. Sheela is a "Westernised", modern woman with an aristocratic background - so modern that she is prepared to be in a hotel room with a man while being engaged to another. In this scene Sheela is endowed with a perspectival address, but from Ram's nationalist point of view, neither her "Westernised" manner nor her perspectival address can in any way be taken as guarantors of a uniformly modernising position. The alternative within colonial and nationalist (and scholarly) discourses that rests on a binary opposition between Indian and "Western" cultures is to mobilise a frontal address. This leaves Ram with a form that, at one level, is held to belong to a pre-modern narrative system, and which, as such, is also held incapable of conveying a subjective, individuated point of view; and, at another level, Ram's frontal address conveys an impersonal, objective discourse pertaining to the political sphere of nationalism. This is not to say that Ram has no subjective dimension. On the contrary, the camera's mobility in this scene seeks to carve out from his frontal address a private or subjective, as well as a public or objective perspective. The tension around Ram's portrayal indicates that the address thus produced does not so much "resolve", as "hold" a tension, within the character of Ram, between different temporalities and concomitant notions of identity. Open both to modernising elements within nationalism opposing colonial rule and to traditionalist power-blocs resisting the modernising aspects of colonial and Congress rule, Ram's frontal address in this scene can thus convey Ram's commitment to nationalism and contain the progressive forces generated by the discourse of nationalist mobilisation, including Ram's individuation, which is dramatised here as, and projected onto, Sheela's sexuality.

The frontal address of Hindi cinema is not, in itself, a pre-modern form. Shaheed offers some indications of some of the socio-historical currents orchestrating the meaning of this address in India in 1948. It shows, for instance, that the struggle against British colonial rule was, and possibly remains, one determining factor in the orchestration of the narrative forms available to the Hindi cinema. Among them, frontality, which, in the Hindi melodramas of the 1950s and after remains available also for the construction of an individuated subject. Guru Dutt's Pyaasa (1957) is a case in point. In this film, Dutt used extreme frontal close-ups on Vijay's face and eyes in order to invest Vijay (played by the director himself) with a psychological dimension and a subjective point of view. At the same time, it is not enough to argue that the dominant mode of address of Hindi cinema is frontal, rather than perspectival, because this cinema emerged from and functioned in a context that responded to realism as a colonial import. There is ample indication in Shaheed that the historical relay at work in the Hindi, as in any, cinema is more complex than a simple binary opposition between India and the "West". While mobilised to out-modern narrative strategies associated with a regressive, colonial constellation, in Shaheed frontality remains simultaneously available to contain 
the individuating trust triggered by nationalist mobilisation and the Congress agenda of modernisation. Contemporary Hindi films such as Hum Aapke Hain Kaun/Who Am I to You? (S. Barjatya 1994) use frontality in this way - blocking the spectators' capacity of one-to-one identification with a character and simultaneously inscribing them into a barely reconstructed hierarchical space. ${ }^{(4)}$

Cultural forms have no substance of their own. They derive their function and meaning from the historical forces which operate "outside" the text and which orchestrate them in their struggle to ascribe meaning to the available cultural stock. The perspectival modes of address which, as used in 1930s European and American cinemas, Lewis Jacobs and later film historians associated with a modern, individuated spectator, cannot be assumed to have the same meaning in a culture such as South Asia, where different speaking positions and historical layers attach to this and other visual regimes. The forces orchestrating the narrative strategies of Hindi cinema and the speaking positions attaching to them are to be identified there, in the historically specific dynamics between the social and the economic spheres that shape Hindi cinema, as an industry and as a cultural practice or cluster of films. ${ }^{(5)}$

This is to say that an understanding of the cinema in India as a force field where South Asians negotiate their encounter with, and particular horizons for, modernisation at any given time must necessarily begin with a better understanding of the economic forces governing over, and defining cinemas in India as an industry regulated, if indirectly, by the Indian nation-state in its relation to global capitalism.

Whereas by the 1950s, Hollywood cinema was the product of a fully corporate venture, the economic priority and operational emphases of which were on production, this has never been the case for the cinema in India, where production is a highly fragmented sector of small-scale units that rely on localised sources of finance (Prasad 1994). A domestic film industry was at work in India by the 1920s. Its growth from the mid-1930s has been narrated as a struggle between two co-existing tendencies: concentration of production around three main studios on the one hand; "regional" or "independent" decentralisation on the other. In reality, the focus on production is misleading and the term "independent" ahistorical. As Madhava Prasad has also emphasised, in practice the 1930s saw the formation of what became by far the most common mode of film finance and production in the decades to follow, also known as the "minimum guarantee policy" system: a financier-distributor advances the money for production under an agreement that assures the producer a minimum return on each film, after which the revenues are shared between producer, distributor and exhibitor. The amount that is fixed as the minimum guarantee is usually the amount loaned to the producer during the making of the film.

In Hollywood too, producers, distributors and exhibitors share what remains after production, distribution and exhibition costs and fees are met, either as part of a externally (agent) stipulated agreement, or because production, distribution and exhibitors are integrated departments within the same studio. However, in India, the balance of power between these three sectors is not the same as in the US.

Contrary to Hollywood, which emerged as the centre for American cinema out of a struggle against Edison's monopoly on production, cinema in South Asia was marked, since the beginning, by a scarcity of equipment. In the 1910s, exhibition was the one sector of the cinema most immediately accessible to South Asians, who, as a rule, were initially confined to exhibit imported material. At the time, licences would be issued by the Raj to mobile projectors, not to the exhibition site, which was often already in use for other types of public activities. Films could be seen in town halls and fair shows, at religious festivals or in conjunction with wrestling matches (Bhaumik 2001: 22-27). Consistent production of Indian features did not kick off until after World War 1, when the population of undivided India, and especially the urban population, began to increase at a very high rate (Desai 2004: 22-23). Unlike imported films, which could be acquired cheaply by the foot and circulated rapidly, generating fast turnovers, locally produced films were expensive to make and, to recover the costs, screened for weeks at a time. By the end of the 1920s, in Bombay at least, exhibition had not only become stratified, with films released first in the up-market theatres of Grant and Lamington Roads, and then traded off to suburban and mill-area halls (Bhaumik 2001: 36), but had also emerged as a means to raise land price. At that point, exhibition of Indian films became more lucrative than that of imported ones.

Distributors of Indian films hardly existed in the 1910s, when producers dealt directly with exhibitors. It remains unclear today if, with the coming of sound, distribution grew in importance. Sound was introduced 
in the 1930s gradually. Initially, due to the cost of equipment and its concentration in a few centres (Bombay, Calcutta and Madras), films would be made in one language and dubbed in the desired regional language(s) after production. Combined with a tripling of the Indian population in the years between the two World Wars (Desai 2004: 22-23), the possibility to show films in the regional languages led to the expansion of the distribution sector. By 1948 there were no less than 887 distributors across India (Barnouw and Krishnaswamy 1980: 145). As these figures suggests, they are certainly not comparable to Hollywood distributors, which have traditionally operated as a cohesive force fully integrated into a monopolistic studio system. After 1947, India was divided into five distribution territories or circuits and external markets regularly reached by Indian films, such as East and South Africa, were sometimes treated as a sixth territory. Today these have further fragmented into a total of twelve domestic territories.

To this day, funding for Indian film production is raised by distributors, who operate at regional level. Rarely do exhibitors fund production, but this is not to say that distributors determine the modalities of film production. India has one of the world's lowest number of cinemas. By controlling the few exhibitions outlets, exhibitors can impose whatever fees they wish, in the process not only determining the amount available to the distributor for film production, but also indirectly presiding over the modalities by which films are made. A breakdown of the capital composition of the Indian film industry in 1968 reveals that, out of a total investment of Rs 4.1 million, Rs 2.6 million (or 60 per cent) were invested by exhibitors alone, while producers and studios' input was no more than Rs 0.6 million (Screen 5 July 1968: 13). ${ }^{(6)}$

Whereas production and distribution have since remained highly fragmented sectors, by the 1960s exhibition had grown into a cohesive force that tended, however, to mobilise local regional capital. The exhibition sector is today the Indian film industry's locomotive. Closely linked to localised land ownership since the beginning of cinema in Bombay in the first decades of the twentieth century and increasingly to real estate speculation from Rajiv Gandhi's economic "liberalization" in the 1980s, the scope and operation of exhibition is crucial to an understanding of the shape and functioning of Indian films, both as commodities and as discursive practices reliant on specific narrative strategies. These are themselves constitutive of India as a cultural and social force field that cannot be reduced to the Indian state's sphere of control. This is also the case for a nationalist film such as Shaheed.

Within any one society, different temporalities co-exist that are associated with interest groups struggling to gain control over the institutions of reproduction and transmission. Texts produced within the context of those tensions necessarily bear the marks of these contending interest groups and the cultural-historical temporalities associated with them. In order to grasp the complex functioning of narrative strategies such as the frontal address in a Indian film of 1948, it is necessary to think of "India" (as of any national formation) not as a fixed entity, but a socio-cultural process, a changing contested set of overlapping frameworks (always temporarily) stabilised by governmental institutions, be they the Colonial administration, the Indian government or the various institutions seeking to regulate [...] the interface between culture and economy within, at any given time, specific territorial limits. (Willemen and Rajadhyaksha 1999: 9).

It is at the level of such interfaces between the cultural and the economic - between the frontal address in Shaheed, Filmistan's national film production and the localised nature of exhibition and distribution capital in Indian cinema - that the adoption of a historiographic model based on the functioning of American and European cinemas, like Jacobs', has created the greatest obstacles to the visibility, the documenting and the understanding of Indian cinema as a social practice with real material functions and effects. Research priorities have tended to stress film production at the expense of all other sectors of the film industry, because, at least until the 1970s, Hollywood was a production-oriented enterprise. The discourse of technology as dictated by the Hollywood mode of production has been projected onto all national cinemas, including India's, even if - perhaps even because - to this day, the Indian film industry relies on technology that is primarily imported. Indian distribution and exhibition, on the other hand, remain largely unexplored areas, even if there are good indications that, if properly researched, they, alone, would offer a far more accurate picture of the functioning of Indian cinemas than existing accounts have been so far able to do.

The fundamental differences between the concrete processes of cultural industrialisation and, more generally, of economic modernisation in India and in the USA or Europe have not prevented film historians from looking at Indian cinemas through the lenses of American and European cinemas, but they have done so 
with all the difficulties, contradictions and erasures mentioned above. My intention here has been to propose a line of enquiry for a reconsideration of film in India, not through the lenses of Euro-American cinemas, but as an adjunct of the long and medium-term social and economic dynamics which have shaped modern India; an agenda for urgently needed future research on the basis of which we may finally arrive at a better understanding of where the diverse cinemas of India must have come from, of how they function within a global process of industrialisation as encountered by Indian society, and of the nexus between that and the reshaping of Indian people's habits and lives through, precisely, the narrative strategies of Indian cinemas.

\section{Notes}

1. Hubert Damisch (1994) has shown that this is also the case for visual perspective, which, as Michel Foucault has also written, subsumed god's monocular vision.

2. I would like to thank Ashish Rajadhyaksha for drawing my attention to this scene.

3. Regarded as the man who brought Shakespeare to the Indian screen, Modi went beyond the Parsi theatre for his choice of themes. His formal approach, however, "remained tied to it and evokes the way Parsee theatre looked and sounded, using frontal compositions and staging the narrative in spatial layers." (Rajadhyaksha and Willemen 1999: 150).

4. For a comparative analysis of hierarchical spaces in the Hindi films Pakeezah (K. Amrohi, 1961) and Hum Aapke Hain Kaun see Vitali (2000).

5. For a similar argument in relation to Korean cinema, see Willemen (2002).

6. While this proportion may not seem pertinent because, as Madhava Prasad has argued, exhibitors' capital is not pumped back into film production, it is essential that it be seen as part of the interlacing of the film industry with the Indian economy as a whole. Exhibitors' capital does circulate across cinema and other economic sectors, most notably in real estate and finance, but this does not make such capital any less relevant to Hindi cinema. On the contrary, it reveals the dynamics which shape cinema's embedding in India's social and economic fabric. Only a fraction of this capital circulates within the networks directly controlled by the Indian state.

\section{References}

\section{Bibliography}

Barnouw, Erik and Krishnaswamy, S. Indian Film. Second Ed. New Delhi: OUP, 1980.

Barthes, Roland. "Lesson in Writing" in Image, Music, Text. Glasgow: Fontana, 1977.

Bauer, Otto. "The Nation" in Gopal Balakrishnan (ed) Mapping the Nation. London and New York: Verso 1996, 39-77.

Chatterjee, Partha (ed). Wages of Freedom. Fifty Years of the Indian Nation-State. Delhi: OUP, 1998.

Damisch, Hubert. The Origin of Perspective Cambridge. Massachusetts: The MIT Press, 1994.

Desai, Meghnad. "India: Emerging Contradictions of Slow Capitalist Development." In Robin Blackburn (ed): Explosion in a Subcontinent Harmondsworth: Penguin in association with New Left Review 1975, 11-50.

Nehru's Hero: Dilip Kumar in the Life of India. New Delhi: Roli Books, 2004.

Gellner, Ernest. Nations and Nationalism. Oxford: Blackwell Publishing, 1983.

Jacobs, Lewis. The Rise of the American Film: A Critical History. New York: Teachers College Press, 1968. Kapur, Geeta (1989) 
"Representational Dilemmas of a Nineteenth-Century Painter: Raja Ravi Varma" in Journal of Arts $\mathcal{E}$ Ideas No. 17-8, reprinted in Kapur, Geeta (2000) When Was Modernism: Essays on Contemporary Cultural Practice in India, New Delhi: Tulika.

Mulvey, Laura. "Visual Pleasure and Narrative Cinema." In Screen 16 (1975), No. 3: 6-18.

Perez, Gilberto. "Who is This Ingrid Bergman?" In London Review of Books, 14 (Dec. 2000), 24-25.

Prasad, Madhava M. The State and Culture: Hindi Cinema in the Passive Revolution. PhD Dissertation University of Pittsburgh: 47. Published in 1998 as Ideology of the Hindi Film: A Historical Construction Delhi. OUP, 1994.

Rajadhyaksha, Ashish. "The Phalke Era. Conflict of Traditional Form and Modern Technology." In Journal of Arts and Ideas 14-15 (1987), 47-78.

Rajadhyaksha, Ashish and Willemen, Paul (eds). Encyclopaedia of Indian Cinema. London and New Delhi: BFI and OUP, 1999.

Vasudevan, Ravi, S. "Shifting Codes, Dissolving Identities. The Hindi Social Film of the 1950s as Popular Culture." In Journal of Arts and Ideas, No. 23-24 (1993), 51-79.

Vitali, Valentina. "The Families of Hindi Cinema: a Historical Approach to Film Studies." In Framework: The Journal of Cinema and Media Vol. 42, Summer 2000.

Willemen, Paul. "Detouring through Korean Cinema." In Inter-Asia Cultural Studies Vol.3 No.2 (Aug. 2002), $167-186$.

\section{Author Information}

Valentina VITALI is a lecturer and researcher at the University of Ulster. Her work on Hindi, Asian-American and Turkish cinema has appeared in Southern Review, Inter-Asia Cultural Studies, Framework, Metro and Filmwaves. She is currently writing a book on action cinema. 